\title{
A Conceptual Framework of Iranian Consumer Trust in B2C Electronic Commerce
}

\author{
Fatemeh Meskaran \\ Faculty of Computer Science and Information Technology \\ Universiti Putra Malaysia, 43400 Serdang, Selangor, Malaysia \\ Tel: 60-1-7287-2220_E-mail: ameskaran@yahoo.com \\ Rusli Abdullah \\ Faculty of Computer Science and Information Technology \\ Universiti Putra Malaysia, 43400 Serdang, Selangor, Malaysia \\ E-mail: rusli@fsktm.upm.edu.my \\ Masitah Ghazali \\ Faculty of Computer Science and Information Systems \\ Universiti Teknologi Malaysia, 81310 Skudai, Johor, Malaysia \\ E-mail: masitah@utm.my
}

\begin{abstract}
$\mathrm{B} 2 \mathrm{C}$ in the developing countries is not yet a normalcy as compared to the developed countries. In this paper, we attempt to improve trust of B2C in Iran. A number of hypotheses are outlined to prove the theories that could improve the trust. A set of questionnaires was designed to reflect hence test the hypotheses. Various related factors are tested in the collective Iranian culture. From the survey, it was found that recommendations by close friends and families are known as an influencing factor on reputation because of the collective culture. In addition, the type of payment is illustrated as an influencing factor on trust as well. Based on the findings, a refined model of Iran Trust Model (ITM) is derived. The model considers the antecedents and the consequences of trust in Iran. A prototype was implemented and tested, in which the prototype - in the form of an e-commerce website that was developed adhering to the model, for a number of weeks. This study examines antecedents and consequences of trust in Iran. Type of payment and reputation are known as the antecedents that related positively to trust. Trust has a negative relationship with risk and a positive relationship with attitude.
\end{abstract}

Keywords: E-Commerce, B2C, Trust, Developing countries, Iran, Iran Trust Model (ITM)

\section{Introduction}

The number of Internet users around the world is growing rapidly and the Internet has become one of the most important means of communication in business activities. However, experts are certain that the Internet has some ways to go before reaching its true potential, especially in the marketing sense. Many experts confirm this state of affairs to be caused by the lack of trust. On the other hand, the acceptance and growth of electronic commerce (e-commerce) and trust to it is different in various regions of the world (Zwass, 1998). Trust in the context of e-commerce beliefs includes the online consumer beliefs and expectancies about trust-related characteristics of the online seller (McKnight and Chervancy, 2002). Despite the growing concern with trust in online shopping and the likely role of national culture on online trust, little is known about how national culture influences the development of consumer trust in online shopping.

Considering the developing and developed countries and the comparison of e-commerce growth between them, the developing countries require more studies and activities on e-commerce. Despite the rapid development of e-commerce in the developed countries such the US and the UK in recent years, the developing countries have a small role in this development. There are many factors that contributed to the development of e-commerce, be it a technical factor such as the system security and communication bandwidth, or a non-technical factor, such as lack of trust and user resistance, and these two latter factors are the two common limitations found in all countries. Having said this, according to Jarvenpaa et al. (2000) trust varies across nationalities and cultures. So studying it in different areas with various cultures is necessary. Consumer choice can be influenced with 
individualistic or collectivistic culture. An individualistic culture may have greater trust and be more willing to base on their trust alone than a collectivistic culture (Jarvenpaa et al., 2000).

There have been numerous studies that present frameworks on trust and its influencing factors with regard to e-commerce. The studies look at the factors that influence trust, the consequences of trust for and trust effectiveness on online behavior (Jarvenpaa et al, 1999; Peszynski and Thanasankit, 2002). Although these frameworks have considered culture as an influencing factor, including Jarvenpaa et al., in 2000 who tested the framework for cross cultural validation, but very few has considered a developing country as their case study. The only extensive work related to this is done by Thompson and Liu in 2007 who developed a trust framework, and considered in their study. Owing to this fact, our study chooses Iran as a case study and from the findings; we present a framework called Iran Trust Model (ITM) that we believe could improve the B2C e-commerce activities in Iran.

Iran has a 12-year history of Internet. People of Iran welcome the technology and use the Internet for gathering information, sending emails and expressing their ideas and thoughts by writing in forums and blogs (Farsnews website, 2006). Despite the popular usage of the Internet for the mentioned purposes, Iran and other developing countries have not yet achieved a reasonable level of e-commerce development. In other words, the e-commerce activities in Iran are not as popular as compared to the generic usage of the Internet, and are as not as common as what is happening in the developed countries. To support the early development of e-commerce in Iran, we can see from a work performed by Koohi (2006), in which he outlines the requirements in implementing e-commerce in Iran that encompasses principles and policies that should be considered in order to implement e-commerce by the Islamic Republic of Iran. Another recent work is carried out by Elahi and Hassanzadeh (2009) in which they studied a number of Iranian companies and suggested a framework for evaluating the e-commerce practiced there. In this framework, all technical, organizational, and inter-organizational dimensions are assessed as part of the evaluation.

Trust as a main barrier in e-commerce growing, in Iran has also been identified as one of the non-technical limitations that hinder the development of e-commerce in the country, in which it was emphasized that because of low security, people don't have the trust and thus, hesitate to send sensitive data.

Although security in e-commerce is perceived and considered as one of the most important limitation for developing countries, the information security issues have been compounded by the lack of trust (Rao, 2002). This is necessarily true for the Iranians as due to the lack of trust on the security, they feel hesitate to send sensitive data online. Thus establishing trust between the parties completing a transaction is the key to the growth of e-commerce in developing countries (Aljifri et al., 2003), particularly in Iran with a collective culture and lack of enough study around it. Trust can be a factor for improving the motivation for online buying. The main aim of this paper is to developing and illustrating a conceptual framework of trust in $\mathrm{B} 2 \mathrm{C}$ e-commerce in Iran.

The Iran culture has low score in individualistic (Hofstede score of 41 out of 100). That is bigger than individualistic score of China (Hofstede score of 20 out of 100). The low score in this dimension indicates the society is collectivist as compared to individualist. This is manifested in a close long-term commitment to the member 'group', that is a family, extended family, or extended relationships. Loyalty in a collectivist culture is paramount, and over-rides most other societal rules and regulations. The society fosters strong relationships where everyone takes responsibility for fellow members of their group (Hofstede, 2007). Members of collectivist culture cannot trust someone that is not in their group (Yamagishi and Yamagishi, 1994).

This study is an extensive work of Meskaran and Ghazali (2007). The model produced in 2007 is refined in this paper. Here, we will first present the hypotheses related to the study. In section 3, we describe the methodology for developing and refining a framework on trust in Iran. Next, Iran Trust Model (ITM) is described and explained as a proposed framework to improve trust. An experiment is carried out in the next section to test the framework by prototyping a $\mathrm{B} 2 \mathrm{C}$ e-commerce website. This is followed by conclusion and discussion.

\section{Hypotheses}

This work focuses on the antecedents and the consequences of consumer trust in an Internet store, and at the same time consider the role of Iranian culture. In this paper, only the consumer awareness of trust is considered whilst the third parties and the trustees aspects are not considered. We will learn whether the customer trust affects customer attitude and risk, and attitude and risk affect customer willingness to buy. The hypotheses of this study are shown in Figure 1. 


\subsection{Reputation and size}

Jarvenpaa et al. (2000), Jarvenpaa et al., (1999) and Thompson and Liu (2007) asserted that perception of reputation of an online shop by customers, affects their trust. In addition, in the traditional marketing reputation is related to the customer trust positively (Ganesan, 1994). Therefore, the first hypothesis of this study is:

H1: The perceived reputation of an online shop is related to consumer's trust positively.

Jarvenpaa et al. (1999) and Jarvenpaa et al. (2000) considered size as a factor that is able to assume the risk of product failure or transit losses. In traditional marketing large size organizations show that the firm has likely a good expertise and support system (Gefen et al., 2005). So this paper follows that:

H2: The perceived size of an online shop is related to consumer's trust positively.

Jarvenpaa et al. (1999) suggested that in the large size stores the consumer has a favorable reputation with the store, and a store with a good reputation cause a larger store. Also in another study by Peszynski and Thanasankit (2002), larger online store is perceived as high reputation and in vice versa. Therefore, perceived size and reputation are expected to be in relationship and the third hypothesis is:

H3: perceived size and reputation of an online store are related together.

\subsection{Recommendation of friends or family}

The results of Sinha and Swearingen (2001) showed that the user's friends consistently provided better recommendations than other recommender systems. Since recommendations about the reputation of a vendor is much better than most other recommendation systems (Swearingen et al., 2001), we hypothesize that:

H4: Recommendation of friends or family and reputation of an online store are related together positively.

\subsection{Physical store}

Having a physical store ensures consumers that requested product is available at the physical place, and it will increase consumer's trust in online shop (Gurau, 2001 and Thompson and Liu, 2007). The consumers can return the online bought products to physical store and get the refund. Also some after sales services will be existed (Thopmson and Liu, 2007). The next hypothesis is:

H5: Having a physical store for online shop is related to consumer's trust in the vendor positively.

\subsection{Type of payment}

Type of payment is a serious effective issue on distrust to online buying especially in developing countries (Efendioglu et al., 2003 and Hawak, 2004). According to Efendioglu et al. (2003), preferred type of payment in different countries with different cultures will be different. For example in China as a developing country, payment by credit card is not common. And type of payment is a major factor for lack of trust. Therefore, the next hypothesis for this study is:

H6: Type of payment for an online shop is related to the level of consumer's trust in the vendor.

\subsection{Consumer trust, attitudes and willingness to buy}

According to TRA (Theory of Reasoned Action) (Ajzen and Fishbein, 1980), beliefs of a person effect on individual attitude and intention to perform behavior are affected by individual attitudes. Macintosh and Lockshin (1997) mentioned the existence of relationships between trust - attitude and attitude - purchase intention. In addition, trust leads consumers to have more positive motivation with the vendor (Thompson and Liu, 2007). So it follows that:

H7: Consumer trust in an online shop is related to favorable attitudes for purchasing positively.

H8: Favorable attitude in an online shop is related to consumer's willingness to buy positively.

\subsection{Trust and risk}

Shemwell et al. (1994) and Ganesan (1994) proposed that trust reduce consumer's perception of risk. Jarvenpaa et al. (1999) and Thompson and Liu (2007) identified risk as one of the consequences of trust. Higher consumer trust in an online shop reduces the perceived risks associated with buying from that shop. Hence the next hypothesis is:

H9: Consumer's trust in an online shop is negatively related to the perceived risk of an online shop. 


\subsection{Risk, attitude and willingness to buy}

According to TRA (Ajzen and Fishbein, 1980) perceived risk has a negative relationship with attitudes toward the purchasing behavior. Thompson and Liu (2007) proposed that perceived risk and attitudes are related negatively. On the other hand, it was stated that when trusting intention is low, perceived risk will be high. Jarvenpaa et al. (1999) and Tompson and Liu (2007) considered this relationship in their framework. Therefore, we hypothesize that:

H10: Perceived risk in an online shop is negatively related to favorable attitudes.

H11: Perceived risk in an online shop is negatively related to willingness to buy.

\section{Methodology}

In order to test the hypotheses outlined above and to develop a framework, a set of questionnaires are outlined. The nature of the questions is in the form of quantitative survey as the paramount of the survey is to discover the antecedents and the consequences of Iranian consumer trust in an online store. The questions are presented using a Likert-scale in which the respondents can choose from strongly disagree (1) to strongly agree (4). A statistical analysis is performed on the achieved results and this is done by using the SPSS tool. Correlation between the antecedents and the consequences of consumer trust is shown by numeric value and measuring mean, standard deviation and bivariate correlation. For the hypotheses testing, path coefficients which have the numeric value are calculated.

300 questionnaires are published and given to Iranian customers. The questionnaires of Jarvenpaa et al. (1999) and Thompson and Liu (2007) were considered for designing the questionnaire. Table 1, summarizes the list of related items to hypotheses. The respondents were asked to consider one online shop as a reference in answering to the questionnaire. They have to choose an online shop that they have recently bought something from, or if they did not have any online purchasing experience they can choose an online shop that they are familiar with. Three main shopping centers in south, middle and north of Tehran are identified. Tehran is chosen as it is the capital city of Iran and it has a complexity of different people of all around Iran (Khosroshahi, 2006). Different people from all cities of Iran with different races come and stay here. 100 questionnaires were circulated to each shopping center.

Supposition model is made of 11 hypotheses. For multi-collinearity problem, correlation coefficients and Variance Inflation Factor (VIF) will be measured. If correlation coefficient of two items of the study is less than 0.8 , then there is no multi channel problem. Large VIF amount causes multi collinearity problem among variables (it should be less than 2). For hypotheses testing, the unstandardized weights estimates are used, because comparison across samples and retaining their scale effect is possible in unstandardized coefficients (Thompson and Liu, 2007). The hypotheses of this study are tested by understanding coefficient of model factors among them.

All relationships that are hypothesized for variables of model are tested. The amount of unstandardized coefficient for every path in model shows the importance of that path. If this calculated amount be a big number it shows that variables related to this path are effective on each others. The negative amount shows a negative relationship. A negative big number shows that there is a relationship but its effect is negative. The small amount for positive or negative amounts shows there is not a considerable relationship. All weak relationship is removed.

A framework will be derived from these results. The next step is to test the framework - which is known as ITM, by designing website based on this framework. This website is a prototype for illustrating the ITM. The effective factors in ITM are considered in this website. A pre-test is run for two weeks by publishing the website on the web, without any advertisement or introduction. The purpose of this phase is to understand the quality of the website. After that, the website address is sent to 50 Iranian students for testing. The influencing factors in ITM are highlighted in the website. The role of these items is evaluated for two weeks testing period, to compare the rate of visitors to customers. After pre-testing and testing, a post testing of framework is also conducted for two more consecutive weeks, again to compare the number of visitors and customers and calculate the rate among them.

This study is extended from Meskaran and Ghazali (2007), in the way that it now focuses on the antecedents and the consequences of trust.

\section{Results of survey}

Out of 300, 267 answered questionnaires were collected. A response rate of $89 \%$ is high for this kind of survey. Among the participants, 94 persons are from Milad Noor, 91 persons are from Shahrvand and 82 persons from 
Refah. Although equal number of questionnaires were distributed to each shopping center (100 questionnaires for each centre), but different responses were received. People in Milad Noor are more likely to answer questions, and some of them like to know the outcome of this survey.

\subsection{First Section of Questionnaire}

This section is about general background of respondent. The profile of a respondent includes name, gender, education, Internet experience and online purchasing experience. Overall, $47 \%$ of responses of this study were male and \%53 persons were female. The gender in Shahrvand and Refah was approximately mixed while in Milad Noor the majority of responses were female (60\%).

As per education, in this study, 38\% holds bachelor degree or higher, and the others were diploma or junior college. The difference of percentage for two different levels of education in Milad Noor is small, but bigger in Shahrvand and Refah. The most percentage of bachelor degree and higher is in Milad Noor with (44\%).

Only $21.3 \%$ of respondents are familiar with the Internet. Shahrvand and Refah respondents had approximately similar result for Internet experience. $13.9 \%$ and $12.4 \%$ of them reported that never used the Internet compared to $9 \%$ of Milad Noor respondents. The most percentage was for people that know the Internet moderately and connect to the Internet at least once a moth. This level has the most amounts in three shopping centers with $16.9 \%, 14.6 \%$ and $12.7 \%$. Finally there are $65.5 \%$ of participants that know the Internet and have worked with it. Only $34.5 \%$ of participants have never used Internet.

As for the experience in online shop, only $35.7 \%$ of participants had an online purchasing experience. It shows that online purchasing has not grown adequately. It needs to have more online activities. The highest percentage of participants in Milad Noor (53.2\%) had an experience in online purchasing. In contast, Refah with only $22 \%$ had the minimum percentage in online purchasing experience.

\subsection{Second Section of Questionnaire}

This section includes 14 questions related to the hypotheses. Each question of this section reflects a considered item or hypothesis in the model. As all questions are scored from 1 (strongly disagree) to 4 (strongly agree), the mean of importance of each variable is equal to 2.5. The considered items or hypotheses in the model are:

Perceived of Reputation (PR), Perceived of Size (PS), Physical Store (PHS), Type Of Payment (TOP), Recommendation Of Friends (ROF), Consumer Trust (CT), Attitudes (ATTD), Perceived Risk (PR), Willingness To Buy (WTB).

\subsection{Mean, Standard Deviations and multi-collinearity problem}

The means and standard deviations of variables are shown in Table 2. According to this table the mean of all variables is more than 2.5 except for PR. This results show that these factors are important for choosing an e-commerce vendor. As it was expected, the mean of risk is below than 2.5 that shows willingness of people to lower risk.

According to Judge et al. (1982), multi-collinearity is considered as a serious problem when correlation coefficient between the items is greater than 0.8 or 0.9 . Correlation coefficient between items of this study is shown in Table 3.

Another indicator of multi-collinearity problem is Variance Inflation Factor (VIF), Large VIF values indicate a high degree of collinearity or multi-collinearity among variables. The amount of VIF for variables of this study is shown in Table 4. According to this table, the VIF of variables in this study are less than 2.0. It shows that there is no multi-collinearity problem.

\subsection{Importance of variables in selecting an e-commerce vendor}

Table 5 shows the answer to the importance of each variable. As answers were scored from 1 to 4 , as when the answer is 2.5, a null situation is shown. According to this table, most of the participants have considered PR when choosing an online shop (83\% in comparison with 17\%). Although most of the participants considered PS as an important factor and the total mean is bigger than 2.5, the number of participants with a mean less than 2.5 is not negligible. As it is shown for PHS, more than 55\% of participants have a mean less than 2.5. Therefore physical store seems not to be an important factor for choosing an e-commerce vendor.

Possibility of choosing the type of payment is an effective factor for more than $75 \%$ of participants. About $80 \%$ of participants acknowledge their friends' recommendation when they choose an e-commerce vendor and it is shows that it is an effective factor. Since Iran has a collective culture, this result was expected. Table 5 shows that most of participants have chosen a trustworthy e-commerce vendor in their mind, with more than $79 \%$ of 
participants trusted the e-commerce vendor, and had a mean more than 2.5. Although there are participants with different attitude for judging about other persons or vendors, but most of participants have chosen a vendor that gave them a good sense.

The negative effect of trust on risk is one of the hypotheses of this study; and only $11 \%$ of participants did not consider risk for choosing an e-commerce vendor. This result was expected because when participants feel there is high risk in an e-commerce vendor they do not chose that vendor. Most participants (79\%) have a mean bigger than 2.5 that show the high willingness to buy from them.

\subsection{Hypothesis Testing}

For testing the hypotheses of this study, the unstandardized weights are used. This is because of the fact that the unstandardized coefficient is comparable across samples and retains their scale effect. The criterion for testing hypotheses is $p=0.05$, so it is not significant if it is 0.10 and when it is less than 0.05 . This was also used by Thompson and Liu (2007) for testing their hypotheses. Unstandardized path coefficients are calculated for each path that is shown in Figure 2. Then quality of relationship is evaluated by attention to amount of this parameter. High positive and negative coefficient significantly shows positive and negative relationship and also shows that independent item have a major influence on dependent item. In contrast, low coefficient does not show any important relationship.

As it was predicted, perceived reputation $(\mathrm{H} 1: \mathrm{B}=0.33)$ and type of payment $(\mathrm{H} 6: \mathrm{B}=0.52)$ have positive relationship with consumer trust in e-commerce vendor. The amount of unstandardized coefficients for $\mathrm{H} 6$ is high and it shows that type of payment for an e-commerce vendor has a strong positive relationship with consumers' trust. On the other hand, high amount of B $(\mathrm{H} 4$ : $\mathrm{B}=0.46)$ in $\mathrm{H} 4$ shows that the recommendation of friends or family about an e-commerce vendor significantly affects on reputation.

In contrast, perceived size $(\mathrm{H} 2: \mathrm{B}=0.034)$ and physical store $(\mathrm{H} 5: \mathrm{B}=0.12)$ do not show strong positive relationship with consumer trust, because of low amount of $\mathrm{B}$. In addition, consumer trust is related strongly to attitude (H7: $\mathrm{B}=0.66)$, and subsequently attitude affect positively on willingness to buy ( $\mathrm{H} 8$ : $\mathrm{B}=0.50$ ).

Consumer trust has a negative effect on consumer risk $(\mathrm{H} 9: \mathrm{B}=-0.44)$ and as shown in Figure 2, it has a high negative number, so $\mathrm{H} 9$ is also acceptable. According to H10, there is a negative relation between consumers' risk and attitude. $\mathrm{B}$ for this hypothesis is a negative high number $(\mathrm{H} 10$ : $\mathrm{B}=-0.37)$ and it confirms the H10. As the last hypothesis, perceived risk has a negative effect on willingness to buy (H11: $\mathrm{B}=0.31$ ).

\section{The proposed ITM framework}

Overall, the results on consequences of consumer trust are similar to findings of Jarvenpaa et al. (1999), Peszynski and Thanasankit (2002) and Thompson and Liu (2007). Relationship between consumer trust and consumers' attitudes and their willingness to buy is positive, as it is shown in Figure 2. Consumer trust has a negative relationship with perceived risk that is also negatively related to attitudes of consumers and willingness to buy. In other word, high level of consumers' trust in an e-commerce vendor decreases perceived risk. As mentioned, perceived risk and attitude have negative and positive relation to willingness to buy subsequently. It is interesting that the paths' weights in relation between attitudes and willingness to buy is higher than paths' weights between consumers' risk and willingness to buy. The importance of the type of payment and choosing the postpaid system by participants can be the reasons for this result. Consumers have a positive attitude to e-commerce vendor and their willingness to buy is high even in high risk situation.

Overall, type of payment is the most important effective factor on trust among other antecedents of trust $(B=0.52)$. Following this item, relationship between recommendation of friends and reputation is the second strongest. Collective culture in Iran can be a reason for this high amount $(B=0.46)$. Reputation $(B=0.33)$ is in the next position.

Contrary to Jarvenpaa et al. model (1999), perceived size is connected to consumer trust with a low weight coefficient $(\mathrm{B}=0.034)$. Figure 2 shows this relationship. This result is similar to Thompson and Liu work (2007). A probable reason for this result can be that the perceived size of an e-commerce vendor does not affect in consumer trust as much as the perceived size of a traditional shop. In proposed framework that is shown in Figure 3, this item is not considered.

Physical store do not have a considerable positive relationship with consumer trust. The low amount of paths weigh $(\mathrm{B}=0.12)$ can be affected by Iran situation, because too many people prefer to buy from overseas. They prefer to buy goods made of overseas and most of foreign brands don't have any branch in Iran. So the existing physical store for the e-commerce vendor as a related factor to consumer trust is not important. 
Figure 3 shows the ITM. It is a conceptual framework for trust in B2C e-commerce in Iran. The main usage of this framework is to improve customer's trust and increase willingness to online buy. According to ITM, trust is directly influenced by perceived reputation and type of payment.

\section{Website Prototype}

An e-commerce website as a prototype is designed based on the proposed ITM framework. The website is divided into tree main sections, sellers, customers and shopping sections. We also have an admin section for controlling the website. Seller section is a registration section for companies who want to sell items or goods. As part of maintaining the authenticity of the website, the manager (admin) of the website then accepts or rejects sellers by checking the seller's information including address, and phone number.

According to ITM, recommendation of friends or family is an effective factor on perceive of reputation and reputation that directly affect on trust. So as to realize this factor, a section for invitation of friends or family is defined and is placed in customer section.

In addition, since discount is an important motivation in online buying in Iran, a special discount is given to the customers who could attract another customer to purchase online. The inviter is automatically informed by the website during the next purchase.

The second influencing factor on trust in ITM is the type of payment that has a direct effect on trust. When a customer decides to buy something from the shopping section he or she can decide about the type of payment. Two types of payment - credit card and payment at delivery are offered in customer section.

The website was built using by using PHP version 5 and MySQL. After completing the prototype, we launched the prototype on a reserved a domain (www.passag.org) in which the passage word is a common word among Iranian people, which means shopping center. The server is UNIX and is located in Malaysia.

\subsection{Procedure}

There were two phases to the study. The pre-test or the first phase of the study was first run for two weeks without any advertisement or introduction. The purpose of this phase was to look for unforeseen problem(s) with regard to the prototype. Visitors who visited the website during this phase who left their contact details were contacted to explain about our study and goals.

Amendments were made to the prototype based on the visitors' comments before it was being launched again for the second phase. Unlike in the first phase, in the second phase, the URL of the website was sent to at least 50 persons of Iranian students who are familiar working with computers and Internet.

\subsection{Results of Testing}

During the two weeks of testing, 37 positive answers among 50 invited customers were collected. As perceived reputation and type of payment are the two main antecedents for trust in ITM, these items are highlighted in the website. Firstly, the role of type of payment is evaluated. The results for this item that are achieved from Figure 2 are presented in Table 6. During this period, we also had some other random visitors and customers. This is shown in Table 7.

Overall, there were 18 customers in the first week and 40 customers in the second week. These results showed that most of visitors preferred payment at delivery time.

The testing was run for the next 2 weeks as a post test. There were 112 new customers from 259 visitors. 71 persons of our customers during these two weeks had an introducer code. These people came to our website and requested to buy because their friends recommended them. Table 8 shows the results for invited and other customers.

As it is seen, the number of customers that have preferred postpaid for payment is obviously more than the customers that preferred credit card. It is probably that, the lack of credit card causes this result. Therefore, an offline message was sent to 37 customers during the testing period asking whether they have a credit card. The achieved results are presented in Table 9.

Only 33\% of credit card owners have chosen credit card as preferred type of payment. It shows that even when consumers have credit card, prefer postpaid because of its low risk.

The number of customers increases over time as shown in Figure 4. In all stages of testing most of the customers preferred to pay at delivery time. Results show that in the pre-test, all customers selected postpaid and the rate was $100 \%$. Also in the testing stage, the rate of postpaid to customer in first week was $95 \%$ and in second week $88 \%$. Although the lack of access to credit card can be a reason for this result, but during these two weeks, only 
$33 \%$ of credit card owners chose credit card as type of payment. In the post-test stage, the rate of selecting postpaid is $89 \%$.

The rate of customers to visitors is an important subject that can show the importance of recommendation of friends or family. According to the results, in the first week of testing, 11 customers among 14 invited visitors show a rate of $78 \%$, meanwhile this rate for other visitors which came to the website themselves, change to $14 \%$. The rate of customers to visitors in second week of testing is $79 \%$ for invited visitors and $20 \%$ for other visitors. It means that $79 \%$ of invited visitors requested to purchase online.

\section{Conclusion}

The growth of e-commerce can create an opportunity for development in countries similar Iran. Online shopping with inclusive characteristics is a major subject in e-commerce. Increasing the number of customers is the main purpose for all online shopping website. Online purchasing is not yet a customary in Iran. To improve willingness to buy among the Iranian customers, more activities are needed.

According to this study, the two main antecedents on trust in Iran are type of payment $(B=0.5)$ and reputation $(\mathrm{B}=0.3)$ in $\mathrm{P}=0.05$. Also recommendation of friends or family $(\mathrm{B}=0.4)$ is an effective factor on reputation. In consequences of trust, we had a similar results with Jarvenpaa et al. (1999) and Thompson and Liu (2007). Relationship between consumer trust and consumers' attitudes and their willingness to buy was positive. Meanwhile, consumer trust had a negative relationship with perceived risk that was also negatively related to attitudes of consumers and willingness to buy.

According to these factors a refined Iran Trust Model (ITM) framework was presented. We use this model to come up with a prototype to further test the two influencing factors on trust - reputation, and, type of payment (Recommendation of friends or family is considered as a important influencing factor on reputation in Iran). From the study, we could see the increase number of website visitors and most importantly the number of website customers, hence we believe this is very much due to the increase in trust. By increasing customer trust we can hope to see more willingness to online buying.

Going forward, we believe the understanding of the role of culture in developing countries is very important to find methods to improve trust in $\mathrm{B} 2 \mathrm{C}$ e-commerce. Having said that, as this study might have different results in another culture, we would like to have comparison study with other collective cultures in different countries.

\section{References}

Ajzen, I. and Fishbein, M. (1980). Understanding Attitudes and Predicting Social Behavior. Prentice-Hall, Englewood Cliffs, NJ.

Aljifri, H. A., Pons, A. \& Collins, D. (2003). Global e-Commerce: a framework for understanding and overcoming the trust barrier. Information Management \& Computer Security, 11. i3,130-138.

Elahi,S \& Hassanzadeh, A. (2009). A framework for evaluating electronic commerce adoption in Iranian companies. Elsiver International Journal of Information Management, 29, 27-36.

Fars News Agency. (2006). Iranian users use more chat and music as search phrase. Available: http://www.farsnews.com/newstext.php?nn=8508270078 (February 4, 2007).

Efendioglu, A. M., Yip, V. F. and Murray, W. L. (2003). E-commerce in developing countries: issues and influences, University of San Francisco.

Ganesan S. (1994). Determinants of long-term orientation in buyer-seller relationships. Journal of Marketing, $58,2,1-19$.

Gefen, D., Rose, G. M., Warkentin, M. and Pavlou, P. (2005). Cultural diversity and trust in IT adoption: a comparison of USA and South African e-voters. Journal of Global Information Management, 13, 1, 54-78.

Gurau, C., Ranchhod, A. and Hackney, R. (2001). Internet transactions and physical logistics: conflict or complementarity?. Logistics Information Management, 14, 2, 33-43.

Hawak, S. (2004). A Comparison of B2C e-commerce in Developing Countries. Electronic Commerce, Research, 4,3, 181-199.

Hofstede, G. (1967-2007), Cultural Dimensions. Available: http://www.geert-hofstede.com/hofstede_iran.html (January 15 2008).

Jarvenpaa, S. L., Tractinsky, N., Saarinen, L., \& Vitale, M. (1999). Consumer Trust ian Internet Store: A Cross-Cultural Validation, Journal of Computer Mediated Communications, 5, 2. 
Jarvenpaa, S. L., Tractinsky, J., \& Vitale, M. (2000). Consumer trust in an internet store. Information Technology and Management, 1, 2, 45-71.

Khosroshahi, P. (2006). Migration from townships to Tehran. Available: http://www.solgunaz.com/Articles/refuge\%20to\%20Tehran.htm, ( June 6, 2008).

Koohi, I. (2006). E-Commerce Implementing Requirements in Iran, Information Technology Journal, 5, 1, 128-137.

Macintosh, G., Lockshin, L.S. (1997). Retail relationships and store loyalty: a multi-level perspective. International Journal of Research in Marketing, 14, 5, 487-97.

McKnight, D. H. \& Chervany, N. L. (2002). What Trust Means in E- Commerce Customer Relationships: An Interdisciplinary Conceptual Typology. International Journal of Electronic Commerce, 6, 2, 35-59.

Meskaran, A. \& Ghazali, M. (2007). B2C In Iran: A case Study to Improve Trust in Developing Countries. IADIS International Conference e-commerce. 129-136.

Peszynski, K. J. \& Thanasankit, T. (2002). Exploring trust in B2C E-Commerce - An exploratory study of Mäori culture in New Zealand. European Conference on Information Systems (ECIS), Gdansk, Poland.

Rao M, (2002), how real is the Internet market in developing nations? Available: www.isoc.org/oti/articles/0401/rao.html (Jun 1, 2007).

Shemwell, D.J., Cronin, J.J. \& Bullard, W.R. (1994). Relational exchange in services: an empirical investigation of ongoing customer service-provider relationships. International Journal of Service Industry Management, 5, 3, 57-68.

Sinha, R. and Swearingen, K. (2001). Comparing recommendations made by online systems and friends. In Proceedings of the DELOS-NSF Workshop on Personalization and Recommender Systems in Digital Libraries.

Swearingen, Kristen and R. Sinha. (2001) "Beyond algorithms: An HCI perspective on recommender systems, Workshop on Recommender Systems, New Orleans.

Thompson, T. \& Liu, J. (2007). Consumer Trust in Electronic Commerce in the United States, Singapore and China, Omega International Journal of Management Science, 35, 22-38.

Yamagishi, T. \& Yamagishi, M. (1994). Trust and Commitment in the United States and Japan. Motivation and Emotion, 18, 9-66.

Zwass, V. (1998). Structure and Macro-Level Impacts of Electronic Commerce: From Technological Infrastructure to Electronic Marketplaces. Available: http://www.mhhe.com/business/mis/zwass/ecpaper.html (February 20, 2007).

Table 1. Model variables

\begin{tabular}{|l|l|l|}
\hline Item & Description & Source \\
\hline $\begin{array}{l}\text { Perceived } \\
\text { Reputation (PR) }\end{array}$ & $\begin{array}{l}\text { This store is well known. } \\
\text { This store has a bad reputation in the market. [reverse] } \\
\text { This store has a good reputation (for honestly and } \\
\text { marketing). }\end{array}$ & $\begin{array}{l}\text { (Ganesan, 1994) } \\
\text { (Jarvenpaa et al., 1999) } \\
\text { (Jarvenpaa et al., 2000) } \\
\text { (Thompson and Liu, 2007) }\end{array}$ \\
\hline $\begin{array}{l}\text { Perceived Size } \\
\text { PS) }\end{array}$ & $\begin{array}{l}\text { This store is a very large company. } \\
\text { This store is the industry's biggest supplier on the web. } \\
\text { This store is a small player in the market. } \\
\text { [reverse] }\end{array}$ & $\begin{array}{l}\text { (Jarvenpaa et al., 1999) } \\
\text { (Jarvenpaa et al., 2000) } \\
\text { (Thompson and Liu, 2007) }\end{array}$ \\
$\begin{array}{l}\text { Recommendation } \\
\text { Of }\end{array}$ & $\begin{array}{l}\text { This store is recommended by my friends. } \\
\text { Because of my friends' recommendation, I check this } \\
\text { website at least for one time. } \\
\text { My friend was satisfied of this website. } \\
\text { First time visiting of an online shop is more interesting }\end{array}$ & $\begin{array}{l}\text { (Swearingen et al., 2001) } \\
\text { (Peszynski and Thanasankit } \\
\text { 2002) }\end{array}$ \\
\hline
\end{tabular}




\begin{tabular}{|c|c|c|}
\hline & $\begin{array}{l}\text { (without recommendation). } \\
\text { Recommendation is always most important motivation } \\
\text { factor for me. }\end{array}$ & \\
\hline $\begin{array}{l}\text { Physical } \\
\text { (PHS) }\end{array}$ & $\begin{array}{l}\text { I can order online and collect products in the physical } \\
\text { stores of this e-commerce vendor. } \\
\text { I can return the goods that I have bought online to any } \\
\text { of this vendor's physical stores and get the refund. } \\
\text { I can request after-sales services offline for any product } \\
\text { that I have bought online from this vendor. } \\
\text { The pricing of this e-commerce vendor's online and } \\
\text { physical stores is usually the same. }\end{array}$ & $\begin{array}{l}\text { (ICSC, 1999) } \\
\text { (Thompson and Liu, 2007) }\end{array}$ \\
\hline $\begin{array}{l}\text { Type Of } \\
\text { Payment (TOP) }\end{array}$ & $\begin{array}{l}\text { I can buy online and pay after deliver. } \\
\text { This store has an option for choosing the type of } \\
\text { payment. } \\
\text { I prefer postpaid system even if I could use other type } \\
\text { of payment. }\end{array}$ & $\begin{array}{l}\text { (Efendioglu et al., 2003) } \\
\text { (Hawak, 2004) }\end{array}$ \\
\hline $\begin{array}{l}\text { Consumer Trust } \\
\text { (CT) }\end{array}$ & $\begin{array}{l}\text { This store is trustworthy. } \\
\text { This store wants to be known as one who keeps } \\
\text { promises and commitments. } \\
\text { I trust this store that keeps my best interests in mind. } \\
\text { I find it necessary to be cautious with this store. } \\
\text { [Reverse]. } \\
\text { This retailer has more to lose than to gain by not } \\
\text { delivering on their promises. } \\
\text { This store's behavior meets my expectations. }\end{array}$ & $\begin{array}{l}\text { (Macintosh and Lockshin, } \\
\text { 1997) } \\
\text { (Jarvenpaa et al., 1999) } \\
\text { (Gefen et al., 2005) } \\
\text { (Jarvenpaa et al., 2000) } \\
\text { (Thompson and Liu, 2007) }\end{array}$ \\
\hline Attitude (ATTD) & $\begin{array}{l}\text { The idea of using the Internet for shopping is appealing. } \\
\text { I like the idea of using the Internet to shop. } \\
\text { Using the Internet to shop is a good idea. }\end{array}$ & $\begin{array}{l}\text { (Jarvenpaa et al., 1999) } \\
\text { (Jarvenpaa et al., 2000) } \\
\text { (Taylor and Todd, 1995) } \\
\text { (Thompson and Liu, 2007) }\end{array}$ \\
\hline $\begin{array}{l}\text { Perceived Risk } \\
\text { (PR) }\end{array}$ & $\begin{array}{l}\text { How would you characterize the decision of whether to } \\
\text { buy a product from this web retailer? } \\
\text { Online purchasing from this e-commerce vendor has a } \\
\text { high probability of losing money. } \\
\text { I believe that the risk of purchasing online from this } \\
\text { e-commerce vendor is very high. } \\
\text { There is a high probability of losing a great deal by } \\
\text { purchasing online from this e-commerce vendor. } \\
\text { Overall, I would label the option of purchasing online } \\
\text { from this e-commerce vendor as something negative. }\end{array}$ & $\begin{array}{l}\text { (Jarvenpaa et al., 1999) } \\
\text { (Houghton et al.,2000) } \\
\text { (Simon et al., 2000) } \\
\text { (Thompson and Liu, 2007) }\end{array}$ \\
\hline $\begin{array}{ll}\text { Willingness } & \text { To } \\
\text { Buy (WTB) } & \end{array}$ & $\begin{array}{l}\text { My willingness to buy from this vendor is good. } \\
\text { The probability that I would consider buying online } \\
\text { from this vendor is not very strong. } \\
\text { How likely is it that you would return to this vendor in } \\
\text { future? }\end{array}$ & $\begin{array}{l}\text { (Macintosh and Lockshin, } \\
\text { 1997) } \\
\text { (Jarvenpaa and Tractinsky, } \\
\text { 1999) } \\
\text { (Thompson and Liu, 2007) }\end{array}$ \\
\hline
\end{tabular}


Table 2. Mean and standard deviations of variables

\begin{tabular}{|l|r|r|r|}
\hline & \multicolumn{1}{|c|}{ N } & \multicolumn{1}{c|}{ Mean } & Std. Deviation \\
\hline PR & 267 & 3.1785 & .87345 \\
PS & 267 & 2.6105 & .96068 \\
PHS & 267 & 2.3446 & .53479 \\
TOP & 267 & 2.8077 & .80909 \\
ROF & 267 & 2.9207 & .84852 \\
CT & 267 & 2.8772 & .81317 \\
ATTD & 267 & 2.7400 & .91705 \\
PRISK & 267 & 1.7846 & .72416 \\
WTB & 267 & 2.9007 & .72449 \\
\hline
\end{tabular}

Table 3. Correlation coefficients of variables

\begin{tabular}{|c|c|c|c|c|c|c|c|c|c|c|}
\hline & & PR & PS & PHS & TOP & ROF & $\mathrm{CT}$ & ATTD & PRISK & WTB \\
\hline \multirow[t]{3}{*}{$\overline{\mathrm{PR}}$} & $\overline{P C}$ & 1 & .031 & $.207^{\star \star}$ & $.297^{\star \star}$ & $.444^{\star \star}$ & $.359 * \star$ & $.152^{\star}$ & $-.165^{\star \star}$ & $.188^{\star \star}$ \\
\hline & Sig. & & .609 & .001 & .000 & .000 & .000 & .013 & .007 & .002 \\
\hline & $\mathrm{N}$ & 267 & 267 & 267 & 267 & 267 & 267 & 267 & 267 & 267 \\
\hline \multirow[t]{3}{*}{ PS } & $P C$ & .031 & 1 & -.062 & .041 & $.161^{\star \star}$ & .041 & .055 & -.069 & .048 \\
\hline & Sig. & .609 & & .311 & .506 & .009 & .506 & .370 & .260 & .433 \\
\hline & $\mathrm{N}$ & 267 & 267 & 267 & 267 & 267 & 267 & 267 & 267 & 267 \\
\hline \multirow[t]{3}{*}{ PHS } & P C & $.207^{\text {** }}$ & -.062 & 1 & $.189 * \star$ & .057 & .082 & -.053 & $-.132^{\star}$ & .005 \\
\hline & Sig. & .001 & .311 & & .002 & .356 & .184 & .390 & .031 & .942 \\
\hline & $\mathrm{N}$ & 267 & 267 & 267 & 267 & 267 & 267 & 267 & 267 & 267 \\
\hline \multirow[t]{3}{*}{ TOP } & $P C$ & $.297^{\star \star *}$ & .041 & $.189^{\star \star *}$ & 1 & $.341^{\star *}$ & $.519 * *$ & $.331^{* *}$ & $-.337^{* *}$ & 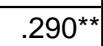 \\
\hline & Sig. & .000 & .506 & .002 & & .000 & .000 & .000 & .000 & .000 \\
\hline & $\mathrm{N}$ & 267 & 267 & 267 & 267 & 267 & 267 & 267 & 267 & 267 \\
\hline \multirow[t]{3}{*}{ ROF } & $P C$ & $.444^{\star *}$ & $.161^{\star *}$ & .057 & $.341^{\star *}$ & 1 & $.484^{\star *}$ & $.294^{* *}$ & $-.282^{\star *}$ & $.242^{\star \star}$ \\
\hline & Sig. & .000 & .009 & .356 & .000 & & .000 & .000 & .000 & .000 \\
\hline & $N$ & 267 & 267 & 267 & 267 & 267 & 267 & 267 & 267 & 267 \\
\hline \multirow[t]{3}{*}{ CT } & P C & $.359^{* \star}$ & .041 & .082 & $.519 * \star$ & $.484^{\star \star}$ & 1 & $.589 * \star$ & $-.489^{\star *}$ & $.495^{\star \star}$ \\
\hline & Sig. & .000 & .506 & .184 & .000 & .000 & & .000 & .000 & .000 \\
\hline & $\mathrm{N}$ & 267 & 267 & 267 & 267 & 267 & 267 & 267 & 267 & 267 \\
\hline \multirow[t]{3}{*}{ ATTD } & $P C$ & $.152^{\star}$ & .055 & -.053 & $.331^{\star \star}$ & $.294^{\star \star}$ & $.589^{\star \star}$ & 1 & $-.291^{\star \star}$ & $.635^{\star \star}$ \\
\hline & Sig. & .013 & .370 & .390 & .000 & .000 & .000 & & .000 & .000 \\
\hline & $\mathrm{N}$ & 267 & 267 & 267 & 267 & 267 & 267 & 267 & 267 & 267 \\
\hline \multirow[t]{3}{*}{ PRISK } & $P C$ & $-.165^{\star \star}$ & -.069 & $-.132^{\star}$ & $-.337^{* *}$ & $-.282^{\star \star}$ & 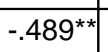 & $-.291 * \star$ & 1 & $-.312^{\star \star}$ \\
\hline & Sig. & .007 & .260 & .031 & .000 & .000 & .000 & .000 & & .000 \\
\hline & $N$ & 267 & 267 & 267 & 267 & 267 & 267 & 267 & 267 & 267 \\
\hline \multirow[t]{3}{*}{ WTB } & $P C$ & $.188^{* \star}$ & .048 & .005 & $.290 * \star$ & $.242^{\star \star}$ & $.495^{\star \star}$ & $.635^{\star \star *}$ & $-.312^{\star \star}$ & 1 \\
\hline & Sig. & .002 & .433 & .942 & .000 & .000 & .000 & .000 & .000 & \\
\hline & $\mathrm{N}$ & 267 & 267 & 267 & 267 & 267 & 267 & 267 & 267 & 267 \\
\hline
\end{tabular}

**. Correlation is significant at the 0.01 level (2-tailed).

*. Correlation is significant at the 0.05 level (2-tailed).

Table 4. Collinearity statistic

\begin{tabular}{|c|r|r|}
\hline \multirow{2}{*}{ Model } & \multicolumn{2}{|c|}{ Collinearity Statistics } \\
\cline { 3 - 4 } & Tolerance & \multicolumn{1}{|c|}{ VIF } \\
\hline PR & .754 & 1.327 \\
PS & .968 & 1.033 \\
PHS & .930 & 1.075 \\
TOP & .838 & 1.194 \\
ROF & .733 & 1.365 \\
\hline
\end{tabular}


Table 5. Importance of variables

\begin{tabular}{|c|c|c|}
\hline Variables & $>\mathbf{2 . 5}$ & $<=\mathbf{2 . 5}$ \\
\hline PR & $83 \%$ & $17 \%$ \\
\hline PS & $57 \%$ & $43 \%$ \\
\hline PHS & $44 \%$ & $56 \%$ \\
\hline TOP & $75 \%$ & $25 \%$ \\
\hline ROF & $80 \%$ & $20 \%$ \\
\hline CT & $79 \%$ & $21 \%$ \\
\hline ATTD & $36 \%$ & $64 \%$ \\
\hline PRISK & $89 \%$ & $11 \%$ \\
\hline WTB & $79 \%$ & $21 \%$ \\
\hline
\end{tabular}

Table 6. The results during test time

\begin{tabular}{|c|c|c|c|c|}
\hline $\begin{array}{c}\text { Weeks / Type of } \\
\text { payment }\end{array}$ & Credit card & $\%$ & Postpaid & $\%$ \\
\hline 1th week & 1 & $9 \%$ & 10 & $91 \%$ \\
\hline 2th week & 4 & $15 \%$ & 22 & $85 \%$ \\
\hline Total & 5 & $13.5 \%$ & 32 & $86.5 \%$ \\
\hline
\end{tabular}

Table 7. The others results during test time

\begin{tabular}{|c|c|c|c|c|}
\hline $\begin{array}{c}\text { Weeks / Type of } \\
\text { payment }\end{array}$ & Credit card & $\%$ & Postpaid & $\%$ \\
\hline 1th week & 0 & $0 \%$ & 7 & $100 \%$ \\
\hline 2th week & 1 & $7 \%$ & 13 & $93 \%$ \\
\hline Total & 2 & $10 \%$ & 19 & $90 \%$ \\
\hline
\end{tabular}

Table 8. Post testing

\begin{tabular}{|c|c|c|c|c|}
\hline $\begin{array}{c}\text { Weeks / Type of } \\
\text { payment }\end{array}$ & $\begin{array}{c}\text { Credit } \\
\text { card }\end{array}$ & $\%$ & Postpaid & $\%$ \\
\hline 3th week-Invited & 3 & $10 \%$ & 26 & $90 \%$ \\
\hline 4th week - Invited & 5 & $12 \%$ & 37 & $88 \%$ \\
\hline Total-Invited & 8 & $11 \%$ & 63 & $89 \%$ \\
\hline 3th week-Others & 1 & $8 \%$ & 12 & $92 \%$ \\
\hline 4th week- Others & 3 & $11 \%$ & 25 & $89 \%$ \\
\hline Total-Others & 4 & $10 \%$ & 37 & $90 \%$ \\
\hline
\end{tabular}

Table 9. Percentage of choosing credit card among credit card owners

\begin{tabular}{|c|c|c|c|c|}
\hline $\begin{array}{c}\text { Weeks } \backslash \text { Type of } \\
\text { Payment }\end{array}$ & $\begin{array}{c}\text { Credit } \\
\text { Card }\end{array}$ & Postpaid & $\begin{array}{c}\text { Credit Card } \\
\text { owners }\end{array}$ & $\begin{array}{c}\text { Rate of credit card column } \\
\text { to credit card owners }\end{array}$ \\
\hline Testing period & 4 & 33 & 12 & $33 \%$ \\
\hline
\end{tabular}




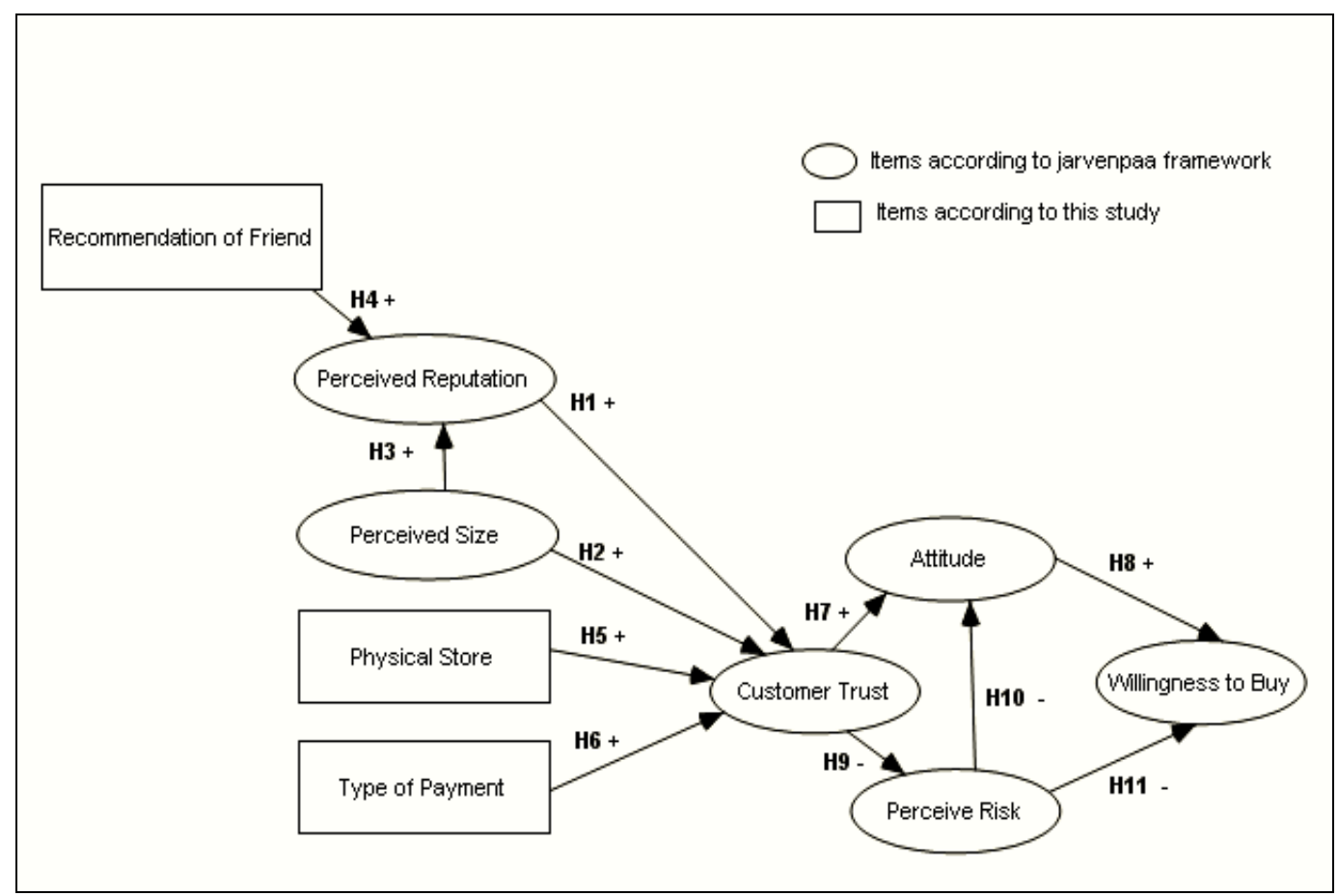

Figure 1. Hypotheses Chart

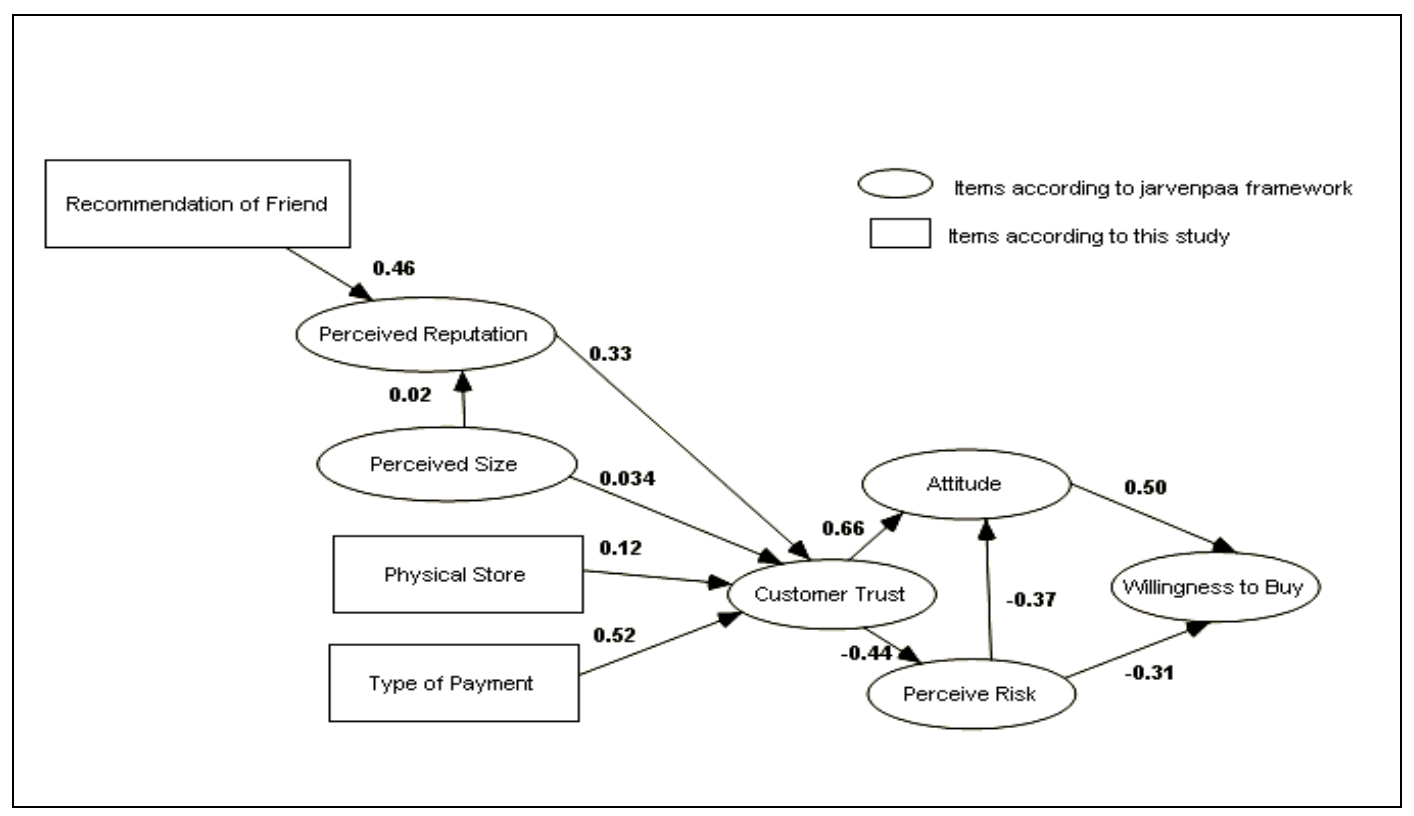

Figure 2. Structural Model (Unstandardized coefficients are shown on arrows) 


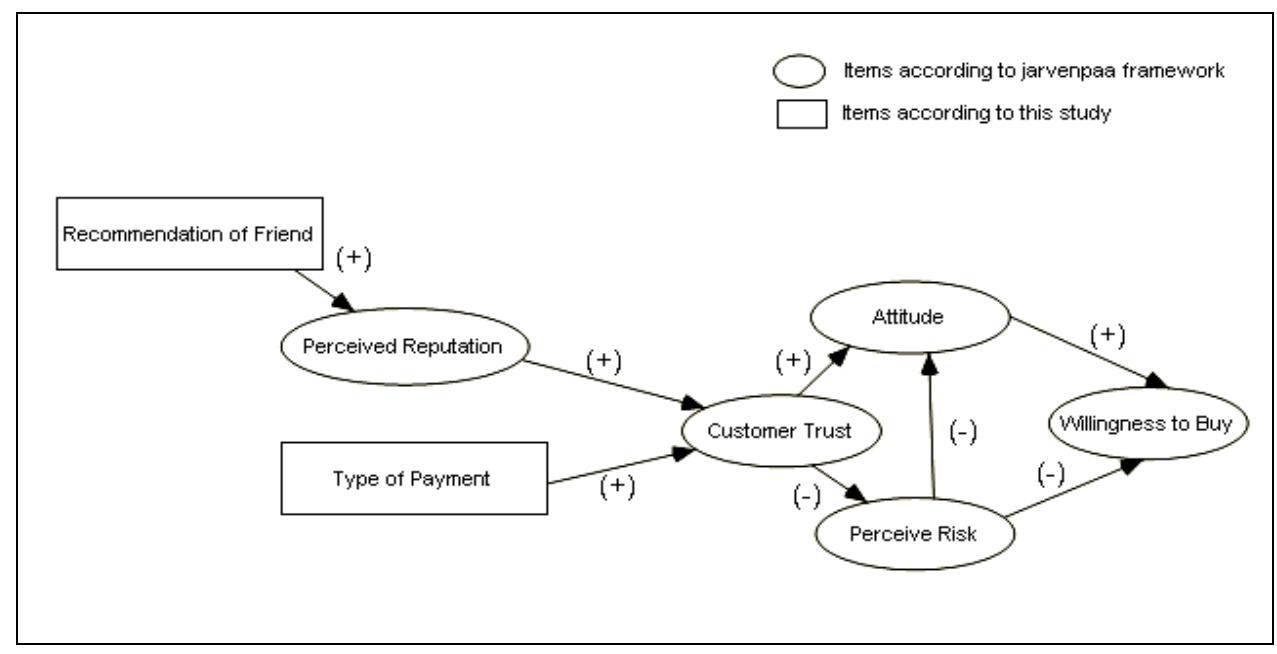

Figure 3. Iran Trust Model (ITM)

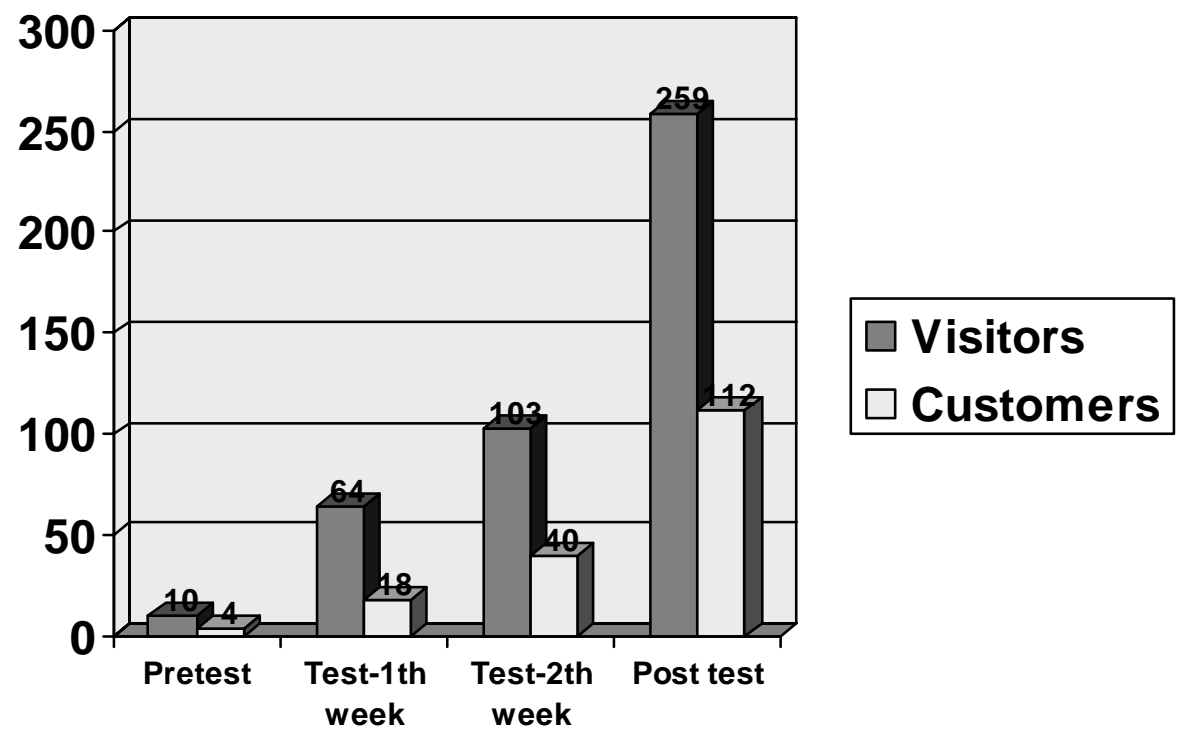

Figure 4. Number of Customers and Visitors 